\section{Dušana}

Findeisen

Skupina Logos -

jezikouno

izobraževanje

\title{
RAZVIJMO SEBE, DRUGE \\ IN S TEM SVOJ KRAJ
}

\section{Neformalno izobraževanje prebivalcev $\checkmark$ lokalni skupnosti}

M strukturiranje industrije $\mathrm{v}$ majhna podjetja. Tudi vizija dolgoročnega krajevnega razvoja, seveda tam, kjer takšna vizija obstaja, ${ }^{1}$ predvideva utrditev sedanje industrije ali razvoj majhnih podjetij, pa tudi razvoj infrastrukture in še marsičesa, kar je bilo nekoč že $\mathrm{v}$ rokah lokalne skupnosti. V novih političnih, ekonomskih in socialnih razmerah in $\mathrm{v}$ obdobju prehoda v tržno gospodarstvo, katerih posledica so tudi nove potrebe ljudi, je lokalni razvoj zelo kompleksen pojav, ki naj bi povezal v skupna prizadevanja najrazličnejše nosilce razvoja: posameznike, velika in mala podjetja, ustanove, društva, pa tudi sektorje, ki sicer med seboj ne sodelujejo in niso povezani. Kadar govorimo o drugačnih potrebah ljudi, moramo poudariti, da so te tudi posledica staranja prebivalstva, preoblikovanja družin, pa tudi potrebe, da bi ohranili krajino in ozdravili onesnaženo okolje ter izboljšali

Lokalni razvoj je danes odvisen od države in lokalne oblasti, mnogo bolj kot nekoč pa od liudi $\checkmark$ lokalni skupnosti. posebne skrbi. To sicer drži, življenjske razmere, ki jih je včasih prehitra ali slabo načrtovana urbanizacija prizadela. V lokalni razvoj se vključujejo vse skupine prebivalstva, tudi tiste, ki imajo samosvoje potrebe in za katere navadno mislimo, da so potrebne pomoči in res pa je, da lahko tudi ljudje s takimi potrebami prispevajo $\mathrm{k}$ skupnosti in da iz tega ne morejo biti izločeni.

Lokalni razvoj ni nekaj, kar bi lebdelo v zraku. Navezuje se na preteklost in trenutno stanje, pogled pa mu sili v prihodnost. Lokalni razvoj brez razvite pozitivne samopodobe kraja v zavesti prebivalcev, lokalni razvoj, ki se ne vključuje v širši sistem lokalne kulture, tj. v kulturno tradicijo, razvoj, ki hkrati ni dovzeten za dosežke drugod in $v$ širšem smi- slu, zastane. Francozi pravijo, da je kultura tisto, kar da našemu bivanju drugačne razsežnosti, ga poglobi in razširi. Rekla bi, da mu omogoča tudi večjo neodvisnost. In kaj je kultura? Opredelitev kulture je nešteto. V lokalnem razvoju nas zanima predvsem tista "prava kultura", kot meni Paul Lengrand v svojem Kulturnem manifestu, kultura, ki je sredi življenja. Na njej bomo utemeljili tudi neformalno izobraževanje prebivalcev v lokalni skupnosti. Tako bomo razvili sebe ter druge in s tem svoj kraj.

\section{LOKALNI RAZVOJ JE RAZVOJ LJUDI}

Lokalni razvoj se začne pri ljudeh in upošteva njihove potrebe. Odgovornost zanj se porazdeli tudi na razne ravni oblasti: državno in lokalno. Večinoma velja, da so lokalne rešitve najbližje ljudem in dostikrat se v zvezi s tem postavi tudi vprašanje, zakaj bi torej lokalni razvoj bil tudi javna, državna skrb? Če bi šlo namreč le za preproste potrebe, bi tržni mehanizmi te potrebe zaznali in se nanje odzvali. Lokalni razvoj pa je javna skrb, kajti na nove, zdajšnje potrebe se trg ne more odzvati sam in ne more sam uveljaviti novih dejavnosti.

Vprašanja lokalnega razvoja so se Francozi z dolgo tradicijo sociokulturne animacije, ki sega prav v francosko revolucijo, lotili zelo izvirno. Povezali so prizadevanja posameznikov, podjetij, ustanov, lokalne oblasti in raznih ministrstev (ministrstvo za gospodarstvo in socialni razvoj, ministrstvo za šolstvo itd.). Že dolgo se srečujejo s tem, kar je pri nas razmeroma nekaj novega, $\mathrm{z}$ odmiranjem industrije. Znano je, da v industriji ne odpirajo novih delovnih mest, da se število delovnih mest povečuje predvsem $\mathrm{v}$ storitvenem sektorju. Kaj torej storiti z mnogimi brezposelni$\mathrm{mi}$, ki jih je industrija izvrgla? Dokler so 
Francozi razmišljali o razvijanju novih panog $\mathrm{v}$ industriji in $\mathrm{s}$ tem $\mathrm{v}$ zvezi le o preusposabljanju brezposelnih prebivalcev, pravih rešitev niso mogli ponuditi. Stvari so se začele premikati šele $\mathrm{z}$ uvajanjem tako imenovane "ekonomije v bližnjem okolju « in "ekonomije solidarnosti «.Oba koncepta so vpeli v vizijo lokalnega razvoja in, kar je posebej pomembno, v sistem lokalne kulture. Naloga lokalnih oblasti in izobraževalcev odraslih ter drugih animatorjev pri tem je, da povežejo lokalno skupnost prebivalcev z gospodarskim sektorjem. V ta namen je treba pomagati, da se oblikujejo lokalni projekti in razvijejo nove dejavnosti ter da se v njih uveljavijo znanje, izkušnje in razvojne možnosti prebivalcev. To seveda pomeni, da se regija ne drobi več na majhne in še manjše občine, marveč to, da te občine iščejo medsebojno povezavo, da se moč odločanja deli med posamezne nosilce razvoja, da lokalna skupnost preizkuša nove oblike gospodarskega delovanja.

\section{LOKALNA SAMOUPRAVA}

Načelu koncentracije moči odločanja na državni in na mednarodni ravni se postavlja po robu drugo politično načelo, ki je utemeljeno s subsidiarnostjo oblasti. Glede na to načelo naj bi lokalne skupnosti prevzele v svoje roke vse zadeve, s katerimi lahko upravljajo. V imenu te politike so bile države decentralizirane $\mathrm{v}$ regije, občine in lokalne skupnosti. Vloga subsidirane države je, da vodi in podpira lokalno skupnost pri njenih projektih.

Po nedavni reorganizaciji imamo dosti večje število občin (147, prej 65). Ustanovitev novih občin je bila odvisna le od volje prebivalcev in ne od tega, ali so lokalne skupnosti zares sposobne opravljati nekatere naloge, ki naj bi izboljšale gospodarstvo, infrastrukturo, kulturo, izobraževanje, zdravje, itd. na posameznem področju. Delež lokalnih skupnosti $\mathrm{v}$ kosmatem narodnem dohodku je zadnja leta znašal med 5,2 odstotka v letu 1993 in 4,2 odstotka v letu 1995. To kaže na to, da je Slovenija lokalnim skupnostim namenila najnižji odstotek narodnega dohodka. Razmeroma visok odstotek bruto narodnega dohodka je $\mathrm{v}$ Sloveniji namenjen državi in drugim centraliziranim službam, razmeroma nizek odstotek pa lokalni samoupravi. V takšnih razmerah občine ne čutijo, da bi morale imeti $\mathrm{v}$ zvezi $\mathrm{z}$ izobraževanjem odraslih in lokalnimi projekti dejavno vlogo. Andragoško poletno šolo, ki jo je oddelek za andragogiko in pedagogiko Filozofske fakultete v Ljubljani ustanovil v Ajdovščini in je namenjena

Nedavna reorganizacija lokalne oblasti v Sloveniji ni potekala v smeri razvoja lokalnih oblasti. Ni šlo za tehniěnoorganizacijsko modernizacijo občin, temveč za oblikovanje novega državnega politiěnega sistema oziroma sistema parlamentarne demokracije s tradicionalno obliko lokalne samouprave. Ta sistem naj bi zamenjal stari sistem občin, $v$ katerem so te delovale kot prva raven državne uprave, vendar so bile pri tem bolj avtonomne kot država sama.

lokalnemu razvoju, smo posvetili tudi širjenju zavesti pri lokalnih oblasteh o njihovi vlogi pri delu z ljudmi in njihovem izobraževanju.

\section{NEFORMALNO IZOBRAŽEVANJE V SKUPNOSTI IN DRUGE OBLIKE ZA RAZVOJ}

Neinstitucionalno ali neformalno izobraževanje $\mathrm{v}$ skupnosti se najbolj razvije takrat, ko pride do velikih sprememb v okolju. To so hitra urbanizacija (npr. v 80. letih), gospodarska kriza ali spremembe kot odziv na pojave brezosebljanja (npr. v Kanadi se je v petdesetih letih kot odziv na brezosebno funkcionalistično arhitekturo pojavila vrsta skupnostnih središč) ipd. Takrat se v okolju pojavi cela paleta potreb, ki jih država s svojimi ustanovami ne more več zadovoljiti.

V državah, kjer je razvito prostovoljno delo, ustanavljajo tovrstne izobraževalne oblike ljudje sami. Najpogosteje so za to potrebni animatorji, izobraževalci odraslih, lokalna oblast ali lokalne izobraževalne ustanove. Izobraževalne ustanove lahko na primer organizirajo izobraževalne programe $\mathrm{v}$ stanovanjskih naseljih, mestnih četrtih ali v manjših krajih, še posebej takrat, ko vlada brezposelnost in se ubadajo $\mathrm{z}$ drugačnimi socialnimi problemi. V Zahodni Evropi se pojavljajo predeli ali mestne četrti, kjer se stopnjuje revščina in kjer je veliko problemov. V Franciji so to na primer spalna naselja, mestna predmestja, na Irskem posamezni mestni okoliši, pri nas morda Maribor, Kozjansko itd. V takšnih predelih neformalno izobraževanje odraslih v skupnosti teži k temu, da bi:

- ponudilo odraslim prebivalcem, da bi z izo- 
braževanjem nadomestili zamujene priložnosti;

- ljudje razvili mehanizme, s katerimi bodo lahko premagovali notranje in zunanje ovire v zvezi z učenjem;

- ljudem omogočili, da analizirajo in razumejo svoje življenje ter družbo, v kateri živijo;

- se povečala usposobljenost ljudi za sodelovanje v skupnosti, v skupnostnem izobraževanju in v akcijah, ki se jih loteva skupnost;

- olajšalo dostop do trga dela in prehod posameznikov k nadaljnjemu izobraževanju.

\section{Lokalna skupnost} naj bi $v$ prihodnosti skrbela za osnovno izobraževanje odraslif.

Neformalno izobraževanje in dejavno druženje ter delovanje v skupnosti je čedalje pomembnejše tudi v našem okolju. To je povsem razumljivo, če upoštevamo politične, ekonomske in socialne spremembe $\mathrm{v}$ zadnjih letih. Lokalna skupnost bo po naših predvidevanjih tista, ki bo prevzela večino izobraževalnih nalog, ki so bile prej v pristojnosti podjetij. Ker so podjetja te naloge večinoma opustila, izginjajo izobraževalna središča, podjetja ne skrbijo več za osnovno izobraževanje odraslih, novih potreb pa je veliko, se bo najverjetneje morala tudi v našem okolju vloga lokalne skupnosti in lokalnih oblasti na tem področju povečati. Temu se bo $\mathrm{v}$ Evropi pridružila tudi zmanjšana vloga države, povečala pa se bo vloga regije.

Poleg neformalnega izobraževanja v skupnosti lahko $\mathrm{k}$ tem ciljem pripomorejo tudi polinstitucionalni programi, ki so dostopni in nastajajo skupaj z ljudmi in jih institucije izvajajo z metodami, ki so najbližje v izobraževanje in projekte vključenim prebivalcem $\mathrm{v}$ kraju.

Takšne programe poznajo na primer na Irskem, kjer je program, ki nastane na ravni države, izhodišče za izvedbene programe $\mathrm{v}$ krajih. Ti programi so namenjeni predvsem brezposelnim, prizadevajo si izboljšati njihovo splošno razgledanost in jim omogočiti dostop do formalnega izobraževanja ter poklicnega usposabljanja. Poleg teh programov so podobno nastali tudi programi za »doseganje mladih ", ki so namenjeni mladim brez pravega cilja pred sabo, mladim, ki niso več v šoli, svet zaposlenih pa jih tudi ne sprejme. Mnogi med njimi so otroci nezaposlenih ali živijo $\mathrm{v}$ marginalnih skupnostih.
Obstajajo pa seveda tudi institucionalni programi s pospešenimi izobraževalnimi načini in programi usposabljanja za odrasle, ki jih vodijo šole in univerze. Sem spadajo tudi programi za vključevanje $\mathrm{v}$ delo.

\section{LOKALNI PROJEKTI NA PODLAGI LOKALNIH POBUD}

Pri lokalnih projektih, ki jih podpremo ali uresničujemo v posameznih krajih, se postavljajo tri velika vprašanja:

1. koliko je posamezen projekt upravičen $z$ vidika razvoja ljudi in kraja;

2. kako uvesti, rekla bi "strukturalno politiko" ali takšno politiko, ki bi omogočila sistemsko oporo nastanku in razvoju lokalnih prizadevanj;

3. katere nosilce razvoja je treba vključiti in navdušiti, da se ta uspešno razvijejo.

Lokalni projekti lahko pripomorejo k odpiranju delovnih mest, vendar se v zvezi s tem pojavi tudi cela paleta posrednih učinkov, ki lahko na koncu tudi ustvarijo delovna mesta. Tako imajo mnogi lokalni projekti izobraževalno razsežnost ali težijo $\mathrm{k}$ usposabljanju, kar učinkuje na lokalni razvoj in tudi na psihologijo prebivalcev $\mathrm{v}$ kraju ter drugih nosilcev razvoja. Učinki lokalnih projektov so takšni, da naredijo družbo dejavnejšo in bolj dinamično. Več se dogaja, več je zamisli in dosežkov.

Evropske raziskave so polkazale, da bi lahko lokalni projekti, ce so upravičent in dobro spodbujeni, v državah Evropske skuprosti v naslednjh petih letih zagotovili od 700.000 do 2,000.000 delovinih mest.

Če razmišljamo o potrebi strukturalne politike, gre pri tem za večjo vlogo države. Ne gre le za finančno pomoč, temveč za to, da država uvede mehanizme, ki bi vplivali na lokalna prizadevanja. Država mora za to razviti juridične mehanizme, zagotoviti denarna sredstva, začeti akcije v posameznih sektorjih. ${ }^{2}$ Tudi lokalna oblast mora voditi razvojno politiko, ki podpira razvoj lokalnih projektov. V Zahodni Evropi je pogosto slišati tudi zahtevo, da bi ljudi, ki so vključeni v lokalne projekte, dodatno izobrazili in usposobili za delo. Tega smo se v Andragoški poletni šoli posebej zavedali. 


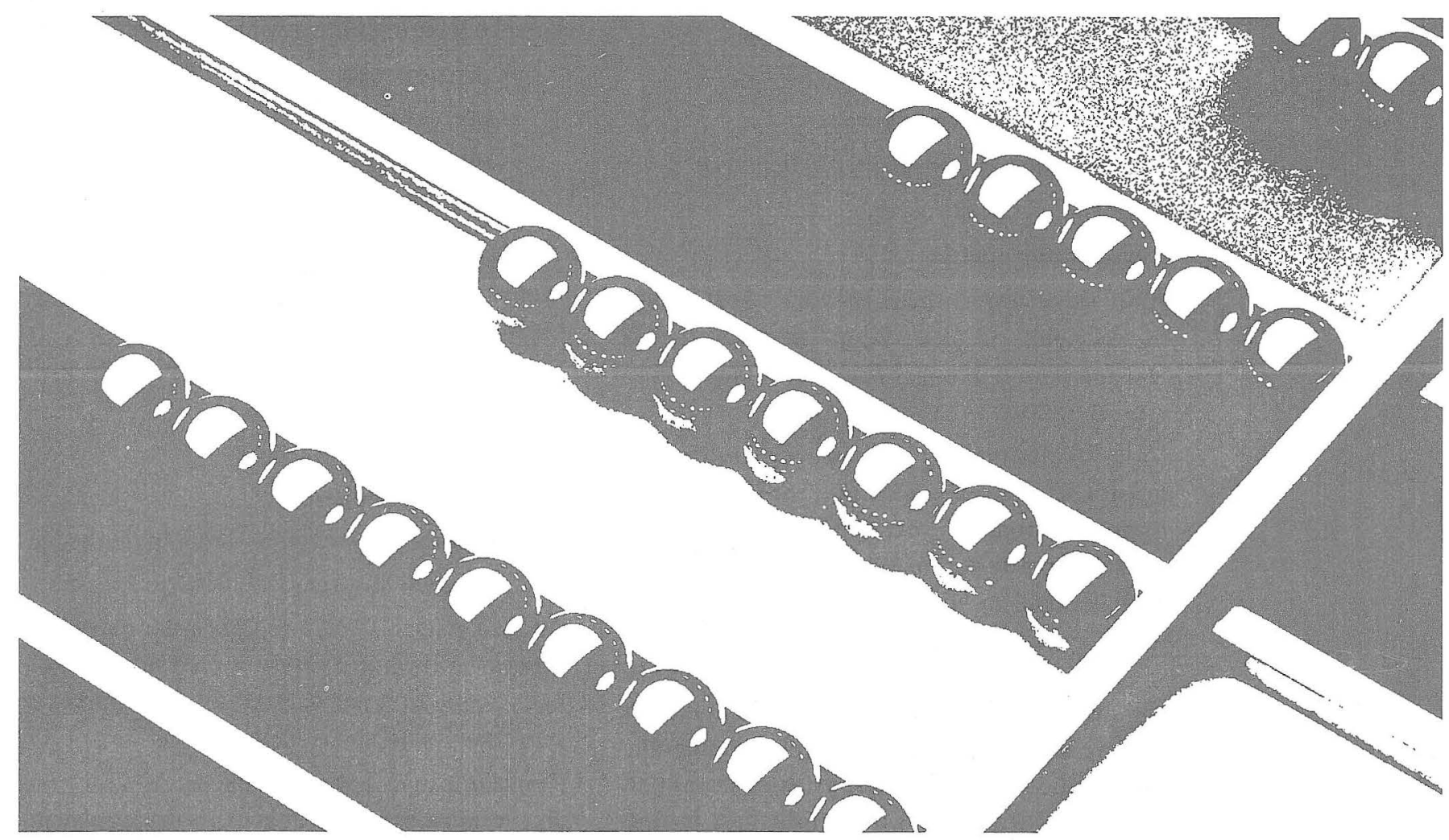

Država kot prvi nosilec lokalnega razvoja mora spoznati, da so projekti usmerjeni od ljudi k državi, in ne nasprotno, kot se je to dogajalo doslej. Država lahko lokalna prizadevanja subvencionira ali vlaga denar $\mathrm{v}$ izobraževanje ljudi, vendar ne sporadično, tu in tam, marveč širše in sistematično, kot se je to pri nas zgodilo s študijskimi krožki ali job-klubi. Pasivni stroški nadomestila za brezposelnost bi bili lahko sicer namenjeni razvoju lokalnih projektov in izobraževanja. Gre torej za drugačne oblike javnih naložb.

Lokalna razvojna politika mora biti v rokah lokalne skupnosti. Lokalna skupnost je drugi pomemben nosilec lokalnega razvoja. Pri tem ne kaže pozabiti podjetij in sindikatov. $\mathrm{V}$ mnogih evropskih državah imajo podjetja vlogo partnerja v lokalnem razvoju, delujejo kot mecen, so opora lokalnemu socialnemu razvoju. Govorijo celo o nekakšni teritorialni državljanskosti podjetij. Nemške izkušnje so pokazale, da je tudi v njihovem interesu, da podprejo lokalne pobude. ${ }^{3}$

Nadaljnjega nosilca razvoja je težje opredeliti. To je civilna družba: družine, posamezniki, prebivalci soseske ali mestne četrti in društva. Ta nosilec ima pomembno vlogo povezovalca ljudi in lokalnih projektov.

Če razmišljamo o razvoju delovnih mest, ne moremo razmišljati le o delovnih mestih samih in človeku proizvajalcu, marveč širše, o človeku, ne le kot delavcu, temveč kot članu družine in širše skupnosti. In kakšna je pri tem naloga skupnostnega izobraževalca ali animatorja, ki si prizadeva za razvoj kraja? Kot že samo ime pove, je namenjena razvijanju skupnosti in izobraževanju.

Naloge za razvoj skupnosti:

- ocenitev problemov;

- zbiranje podatkov, analiza potreb;

- navezovanje prvih stikov z ljudmi in analiza njihovih potreb;

- pogajanje o tem, kaj narediti;

- oblikovanje načinov, sistemov, skupin za začetek in vodenje akcij;

- vzdrževanje in usklajevanje sistemov akcije;

- namensko vplivanje;

- zaokrožitev prizadevanj za spremembe.

Če zdaj ta procesni model primerjamo z modelom, ki ga je dodelal Knowles (1972), v izobraževanju odraslih ugotovimo podobnosti in razlike v zaporedju faz:

Naloge za izobraževanje:

- oblikovanje fizičnega in psihološkega ozračja, 
- skupno načrtovanje izobraževanja,

- ugotavljanje potreb,

- ubesedenje ciljev programa

- načrtovanje zaporedja učnih dejavnosti,

- vodenje učnih izkušenj,

- evalviranje učenja.

Animator skupnostnega razvoja v kraju te faze med seboj preplete, saj gre za delovanje, ki je usmerjeno k dvema hkratnima ciljema: razvoju skupnosti in izobraževanju.

Vsak lokalni projekt, in to smo v Andragoški poletni šoli zelo nazorno pokazali, se začne $\mathrm{z}$ ljudmi in analizo potreb. Ta je namenjena spoznanju o tem, kaj so življenjski problemi ljudi, kakšne so njihove zmožnosti, kaj jih zanima, kakšni so njihovi motivi, pa tudi kakšne so njihove izobraževalne potrebe. Številne spremembe pri nas in v Evropi narekujejo tudi nove izobraževalne potrebe. Te spremembe so privedle tudi do večje odrinjenosti ranljivih skupin na družbeni rob. Zaradi njih je tudi zelo poudarjeno izobraževanje in usposabljanje oziroma preusposabljanje ljudi, kar smo doslej imeli skoraj za edino pot $\mathrm{k}$ zaposlitvi. Z lokalnimi projekti želimo doseči, da se tudi člani marginalnih skupin osebnostno razvijejo in kot člani skupnosti, $v$ katerih živijo, in si tako izboljšajo možnosti za življenje.

\section{Analiza potreb je izjemno pomembna pri načrtovanju izobraževalnega in akcijskega programa.}

Analiza izobraževalnih potreb je potrebna $\mathrm{z}$ vidika izbora vsebin in metod učenja ter delovanja, ki jih bomo uporabili pri lokalnem projektu. Zanimivo pa je to, da ko govorimo o potrebah, ne govorimo le o potrebah članov skupine, ki sodelujejo pri lokalnem projektu, marveč tudi o potrebah vseh drugih partnerjev, tj. mentorja, skupnostnega izobraževalca in tistih, ki projekt vodijo in z njim upravljajo.

Potrebe ljudi:

- pridobivanje ljudi za projekt

- dostopnost projekta

- izobraževalni cilji

- program

- metode

- ocena dosežkov
Potrebe skupnostnih izobraževalcev:

- učne metode

- ocenjevalne spretnosti

- oporna struktura v ozadju

- upravne in organizacijske spretnosti

- spretnosti pri povezovanju projekta v mrežo.

Potrebe vodij:

- oblikovanje projektne skupine

- motivacijske spretnosti

- pogajalske spretnosti

- javno nastopanje

- skupno načrtovanje učenja in delovanja

- upravne in organizacijske spretnosti.

Analiza potreb seveda ni enkratna, marveč je proces, ki traja in se kaže $\mathrm{v}$ vseh fazah lokalnega projekta: med učenjem in delovanjem se potrebe močno spreminjajo.

Programiranje izobraževanja za lokalni projekt je tako predmet dogovora in dogovarjanja z vsemi udeleženimi. To pomeni nove izzive za vse udeležene, to je:

- izobraževalce - oblikovalce izobraževalnega programa, ki so doslej samostojno pripravljali programe, brez sodelovanja ljudi;

- ljudi v kraju, ki se v projekt vključijo, se učijo in so bili doslej bolj ali manj pasivni v odzivih na svoje izobraževalne potrebe;

- skupnostne izobraževalce, ki so morda doslej imeli opraviti le s programi, katerih cilj je bil pridobivanje znanja.

\section{POTREBA PO SPORAZUMEVANJU V SKUPNOSTI IN ZUNAJ NJE}

Dewey trdi, da je sporazumevanje ena izmed bistvenih značilnosti skupnosti in da brez njega ta ne obstaja. Delo v Andragoški poletni šoli je pokazalo, da je $\mathrm{v}$ naših razmerah pomembno ne le sporazumevanje v skupnosti, temveč širša usposobljenost vseh članov skupnosti, da se sporazumevajo tudi z okoljem, in sicer pisno in ustno. Pomembno je, da se usposobijo za vodenje široke kampanje, da vedo, da se zavedajo, da imajo pravico povedati, kar vedo, in da pričakujejo, da jim bodo drugi prisluhnili. Uspešno sporazumevanje je tudi podlaga za to, da ljudje iz marginalnega položaja stopijo v središče dogajanja, si pridobijo politično, ekonomsko in psihološko 


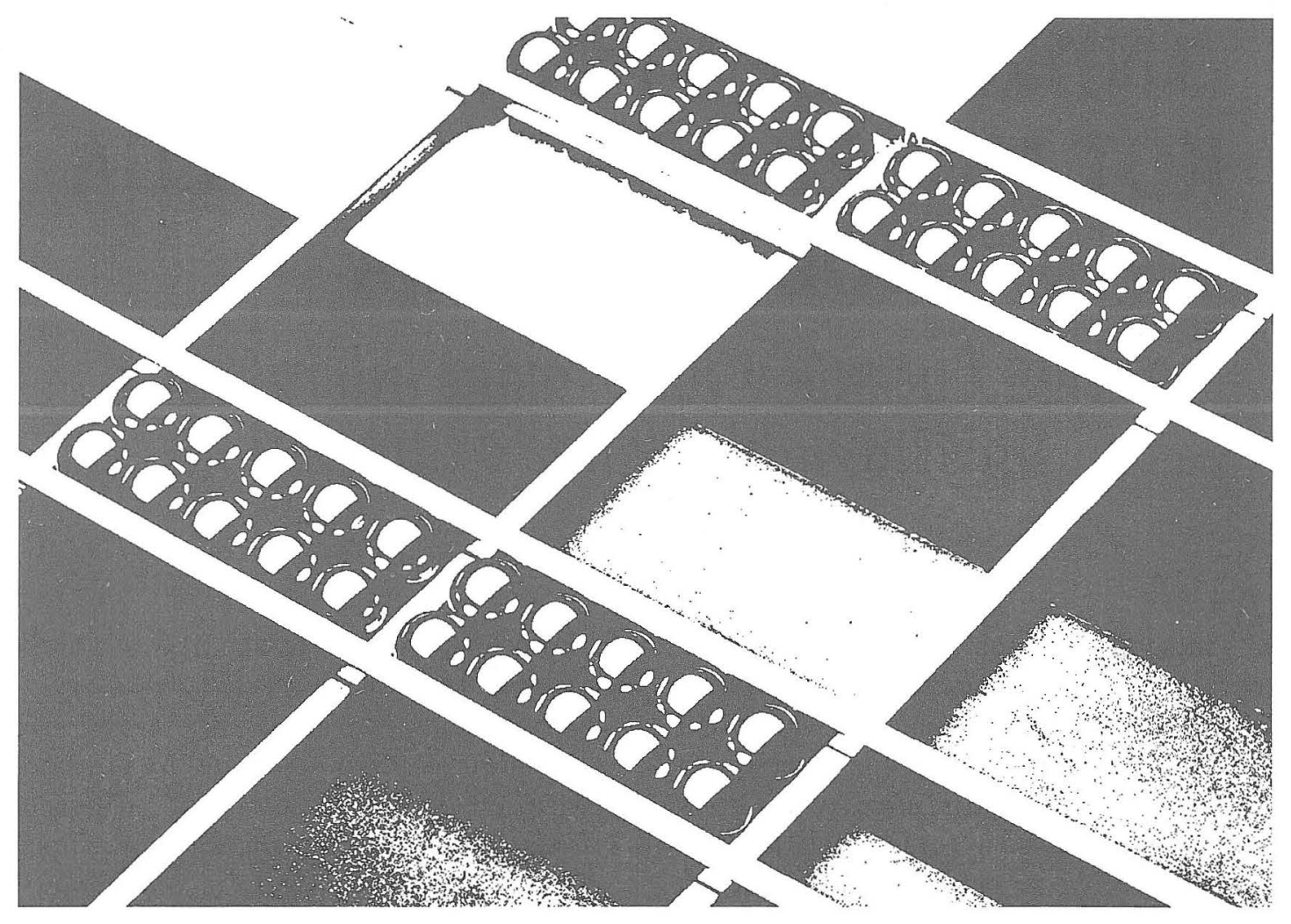

moč, ki jo v današnjih, spremenjenih, okoliščinah tudi potrebujejo.

\section{SKLEPNE MISLI}

Lokalni razvoj ljudi in s tem tudi njihovega kraja je torej $\mathrm{v}$ rokah različnih nosilcev: je javna skrb, skrb lokalnih oblasti in lokalnih skupnosti samih. V lokalnem razvoju kaže v spremenjenih okoliščinah iskati rešitve za zadostitev mnogih novih potreb, ki jih ne morejo zadovoljiti le tržni mehanizmi. Lokalni razvoj ustvarja delovna mesta, vpliva na ljudi in kraj, če se prizadevanja vseh nosilcev združijo okrog dolgoročne vizije.

\section{LITERATURA}

Pascqueur, B.: Mener un projet de developpement local, Les editions d'organisation, 1997.

Hautecoeur, J. P.: Alpha 92, Current Research in Literacy: Literacy Strategies in the Community Movement, Culture Concepts, Toronto, 1992.
Andragoška spoznanja: Skupnostno izobraževanje in lokalni razvoj - priloga, št. 3, Gospodarski vestnik, Ljubljana, 1996.

Communes et developpement durable. La revue de la democratie locale. ADEL, Association pour la democratie, No 369, junij, 1996.

Rayssac, G. L.: Nouvelles activites, nouveaux emplois: quelles strategies de developpement. Actes du Colloque d' Opio des 23 et 24 Mars, 1995, Commission Europeenne, Direction Generale de l'Emploi, des Relations Industrielles et des Affaires Sociales.

Predpisi o lokalni samoupravi. Uradni list Republike Slovenije, Ljubljana, 1995.

Šmidovnik, J.: Lokalna samouprava, Cankarjeva založba, 1995.

${ }_{1}$ Da bi ugotovili, ali vizija obstaja, smo lokalnim oblastem postavili vprašanje, ali vedo, kakšna bo podoba njihovega kraja čez dvajset let. Večinoma nam niso odgovorili.

${ }^{2} \mathrm{~V}$ Španiji so tako uvedli šole - delavnice, ki omogočajo tudi ljudem z nizko ravnjo usposobljenosti, da pridejo do delovnih mest.

${ }^{3}$ Lokalne pobude so $v$ Nemčiji vodile $k$ ustanovitvi jasli za otroke od rojstva do 3 let. 